\title{
A Life-Line for the Pedagogic Goose: Harnessing the Graduate Perspective in Arts Education
}

\author{
Amanda Tinker ${ }^{1, *},+$, Katherine Greenhough ${ }^{2,+}$ and Elizabeth Caldwell ${ }^{3,+}$ \\ 1 School of Art, Design and Architecture, University of Huddersfield, Huddersfield HD1 3DH, UK \\ 2 School of Human and Health Sciences, University of Huddersfield, Huddersfield HD1 3DH, UK; \\ K.J.Greenhough@hud.ac.uk \\ 3 The Library, Lancaster University, Lancaster LA1 4WY, UK; e.caldwell@lancaster.ac.uk \\ * Correspondence: a.tinker@hud.ac.uk \\ $\dagger$ These authors contributed equally to this work.
}

Received: 17 September 2018; Accepted: 19 November 2018; Published: 26 November 2018

check for updates

\begin{abstract}
Studio-based art and design education provides high levels of individual attention but has been criticized for the high demands for space and staff time that it places on institutions. Furthermore, retention and attainment rates in art and design subjects demonstrate that not all students develop the supportive, individual relationships with their tutors that facilitate development as creative practitioners. This article reports a case study of an initiative to improve retention amongst first year students studying Art, Design and Architecture subjects, by utilizing recent graduates, employed as Graduate Teaching Assistants (GTAs), to create a communications bridge between new students and their subject tutors. The project found that retention rates improved by $50 \%$ for these first-year students, who also reported that GTAs are welcoming, approachable, more accessible, and easier to talk to than academic staff. Tutors felt that communication with their students was enhanced by GTAs helping build clear narratives for each student. As the role of GTA becomes more established, further developments will include facilitating peer-to-peer collaboration in the studio through the harnessing and integration of peer mentors to more quickly foster a collaborative and supportive studio culture for new students.
\end{abstract}

Keywords: art and design pedagogy; graduate teaching assistant; higher education; art education; retention; student engagement; student experience

\section{Introduction}

Art and Design education has often been characterized as having a particular pedagogy located in the studio and involving student-centered, practical, and interactive teaching practices (see Elkins 2001; Sims and Shreeve 2012; Orr and Shreeve 2018). Formal didactic content transmission is minimal, and instead students learn by making and doing, and thus "develop ways of knowing through experience of the tactile, visual and spatial", and which are "illusive to those outside our community" (Austerlitz et al. 2008, p. 139). One student in a study by Orr et al. (2014, p. 37) described this style of teaching as: "We never had a lecture like where we sat down". Art and design education also involves "identity transformation" (Orr and Shreeve 2018, p. 3) as students are inducted into the world of studio culture and professional practice.

As Smith and Smith (2012, p. 93) describe, "The studio is a unique education and professional setting with its own methods, practices, traditions, culture, and emotional investments", and studio facilitators must employ "different socio-academic processes" (p. 92) to those utilized by teachers in other disciplines in order to help students to negotiate "the unpredictable, cyclic fluidity of design" (p. 93). Orr et al. (2014, p. 39) describe the role of the studio tutor as a "midwife for the student work", 
but a number of authors also have highlighted the fact that studio teaching is both time and space intensive (Dineen and Collins 2005; Smith and Smith 2012; Swann 1986). Dineen and Collins (2005, p. 50) likened art and design education to a pedagogic goose that can lay the golden egg of nurturing individual creativity, were it not for the fact that it is increasingly "neglected and un-nourished" by the recent trends of managerialism and marketization in higher education.

The term "graduate teaching assistant" refers to a range of roles in higher education, from part-time teaching undertaken by doctoral students to full-time tutor support roles carried out by recent graduates. Graduate teaching assistants are commonly seen as "a solution to ever-increasing teaching loads" (Raaper 2018, p. 424), and much of previous literature on graduate teaching assistants has been critical, due to a perceived threat to the university teaching profession or the precarious nature of employment experienced by many graduate teaching assistants (Smith and Smith 2012; Raaper 2018). Despite this, part-time teaching by PhD students has been a feature of universities for decades, particularly in the sciences, and full-time university teaching assistant posts are increasingly being created by universities keen to enhance the student experience. Smith and Smith (2012, p. 91) describe the latter type of teaching assistant as "someone who lends support to teachers but provides no direct instruction to students", and their recent entry into higher education settings echoes the recent growth of the teaching assistant role in primary and secondary education (Hammersley-Fletcher and Lowe 2011). It is this full-time, teaching assistant role undertaken by recent graduates in universities that is the focus of this article.

According to Smith and Smith (2012, p. 92), the use of teaching assistants in art and design education is a fairly recent trend and there has been "virtually no research" on how teaching assistants are used in studio teaching. This article aims to address this paucity of research by detailing a case study where graduate teaching assistants have been used to enhance engagement for first year undergraduate students studying art and design courses. Given the changing higher education landscape and the ever-increasing pressures on art and design educators, this article explores whether the graduate teaching assistant role has the potential to represent a lifeline for the pedagogic goose that is studio-based art and design education.

\section{Literature Review}

\subsection{The Changing Higher Education Landscape}

UK higher education has witnessed unprecedented changes and challenges over the last twenty years, ever since the Dearing Report (Dearing 1997, p. 101) advocated the value and need to increase participation from previously underrepresented groups "as a matter of priority" and universities were given incentives to rise to this challenge, which became known as the widening participation agenda. This coincided with an introduction of loans and tuition fees of $£ 1000$ per student per year of study, which in England and Wales have successively increased threefold since their inception in 1998, with a "higher-than-expected share of universities charging the maximum fees (in 2016, all but three of the top 90 institutions charged fees of $£ 9000$ per year for all of their courses)" (Belfield et al. 2017, p. 5). Seeking to secure "a sustainable future for higher education", as promised by the controversial Browne review (Browne 2010) and tuition fee reform in 2012, financial investment in the future of universities has increased, yet, at the same time, so have student expectations.

In response, the Higher Education and Research Act (2017) heralded a new regulatory landscape, most notably the Teaching Excellence Framework, awarding institutions Gold, Silver or Bronze status based on three proxy metrics of student satisfaction from the annual National Student Survey (NSS), non-continuation statistics and graduate level employability, and graduate outcomes (HESA 2018), together with a qualitative institutional narrative. With the aim of this making perceived teaching quality more transparent and facilitating informed student choice, the policy seeks to represent and protect student interests through the creation of the Office for Students (2018) to ensure students receive "value for money", a concept typically residing more comfortably in service transactions than in the traditional 
culture of higher education. Although inclusion of universities within the Consumer Rights Act (2015) has certainly signaled the beginning of a relationship change, cementing "advantages for the student because it involves a shift in power from provider to consumer" (Bunce et al. 2017, p. 1959).

What is actually meant by "value for money" in terms of higher education, however, is currently the subject of much discussion and debate (Universities UK 2017; McRae 2018), with a related consultation on student tuition fees currently underway (Department for Education 2018). However, whether students actually view themselves as consumers has been the focus of a current survey by ComRes on behalf of Universities UK (2017), reporting that 47\% viewed themselves in this respect whilst the other $53 \%$ did not. Commenting on the survey findings, Nicola Dandridge, Chief Executive of Universities UK (2017), stressed that clearly "Students value a personalized and collaborative relationship, rather than a superficial consumer transaction. While students have clear expectations of their university, they also expect to shape their own experience." The challenge for universities, then, is meeting and managing these potentially more demanding student expectations for an individualized experience in the context of increasing student fees, diversity and numbers, marketization, and a consumer-focused agenda. With its tradition of personalized studio teaching, arts education should be characteristically well-placed to respond to this. However, at a time when this volatile political climate is starting to challenge the sustainability of long-established pedagogies, research is concurrently indicating that not all arts students are successfully engaging, continuing, and attaining in their studies and with their wider university community (see Finnigan and Richards 2016).

When considering interventions to address issues of student retention and attainment, there is strong evidence that "one size does not fit all" (Thomas et al. 2017, p. 10). Understanding the local context and factors impacting on retention and attainment is essential to provide effective interventions. Structured, supportive working across the institution to enhance the student experience and engagement is considered to be a key element. The framework of student engagement described by Kahu and Nelson (2018) proposes that the student experience is situated within an educational interface within which students' self-efficacy, well-being, belonging and emotions influence their relationship with the institution and their overall engagement and achievement. According to Thomas et al. (2017, p. 3), it is the "human side of education that comes first-finding friends, feeling confident and, above all, feeling part of your course of study and institution". Interventions that can develop a sense of well-being and "belonging" can provide the necessary starting points for increased engagement and academic success.

Evidence from the initial "What Works" programs (Thomas 2012) identified that it is the intended outcomes of an intervention and the mode of delivery rather than the exact type of activity that is crucial. Successful interventions shown to improve student retention and success were well-timed, embedded, collaborative, proactive, relevant, and monitored. Whilst interventions such as peer mentoring enabled students to develop supportive peer relationships, it was meaningful interactions and communication with staff which provided a greater sense of "belonging" and well-being. Additionally, interventions which appeared relevant with a clear academic purpose enhanced student engagement and academic practices.

\subsection{Art and Design Pedagogy: Opportunities and Challenges}

The economic pressures and changing political landscape outlined above produce a particular set of opportunities and also challenges for the studio-based pedagogies of art and design education. On the one hand, the personal and individualized teaching found in studio-based subjects could be seen as providing the more personalized education that contemporary students want. As Dineen and Collins (2005, p. 48) point out, studio teaching "narrows the gap between the teachers and the learner, which cast[s] the teacher in the role of facilitator and provide[s] opportunity for active, even playful engagement by learners". On the other hand, with ever greater student numbers and the consequent drives for efficiency, the heavy demands that studios make on institutions in terms of space and staff time mean that the studio "is frequently seen as a luxury that can no longer be afforded" (Sims and Shreeve 2012, p. 64; see also Swann 1986). Moreover, art and design students 
frequently rate satisfaction with their courses lower than students in other subjects (Austerlitz et al. 2008; Orr et al. 2014) and art and design students have lower continuation and attainment rates than students on other courses (Finnigan and Richards 2016). As Orr et al. (2014) point out, conceptions of "value for money" may mean that "if the students do not fully recognize the lecturers' framing of their learning, then they may wonder what their fees are paying for" (p. 41) and, as such, "they may expect to be taught in a more explicit way than experienced in the traditional art and design studio" (p. 42).

Whilst much of the experiential knowledge of the practice of art and design cannot be transmitted via texts, students are expected to be able to "to speak and understand the language of their particular practice" and to explore verbally "the understanding we construct around artifacts" (Austerlitz et al. 2008, p. 141). Much of this is developed through the social and interactive nature of the studio and dialogic "crit", jury, or presentation sessions that often comprise both formative and summative assessment in many art and design courses. The briefs that students work to are frequently, and deliberately, open to a wide range of creative responses from students and to help them to develop experiences dealing with ambiguity and the unknown, as "'not knowing what to do' is often the origin of innovative ideas" (Austerlitz et al. 2008, p. 144). However, several studies have documented the confusion and disorientation that students experience with this process, at least initially (Sovic 2008; Akalin and Sezal 2009; Orr et al. 2014). Not only do they have to deal with the openness of briefs and a lack of formal teaching, many students also have to "change their mode of operating and reconstruct their way of thinking ... [as] work produced within a particular aesthetic context is no longer acceptable in the culture of higher education" (Austerlitz et al. 2008, p. 134; see also Caldwell and Gregory 2016). Despite the initial bewilderment, many students do eventually experience a feeling of empowerment when they realize the "answer is brought about from within you" (Orr et al. 2014, p. 38) and they start to appreciate the freedom that this style of education can engender (Caldwell and Gregory 2016). As Orr et al. (2014, p. 38), explain, "Students do not receive an art and design education — they are supported in educating themselves and they 'own' their work ... the lecturer's role is that of a facilitator".

A number of authors have suggested that not only is there a gap in expectations between students and tutors, but that the studio is "not simply a place" (Sims and Shreeve 2012, p. 57), but "a state of mind" (Orr and Shreeve 2018, p. 156), and can also be seen as a culture that students must adjust to in order to successfully operate within. Orr et al. (2014, p. 138) suggest that the narratives of the final year art and design students in their study point to a strong level of "enculturation". Austerlitz et al. (2008, p. 138) also point out that "the term induction suggests that students need to adapt themselves to our ways of being and doing. For some students, for those with the right cultural capital, this is not a problem, but for others the failure to adapt becomes 'their problem'" (see also Burke and McManus 2011; Richards and Finnigan 2015). As such, there is a need to search for and bridge gaps in expectations and understanding of what it is to study art and design in higher education in order to help students fulfill their potential and succeed in this environment.

The aim of this article is to assess the contribution of an initiative to foster a sense of belonging and improve the retention of students on art and design courses through the use of graduate teaching assistants (GTAs). The next section introduces the background to the initiative, both at a national and institutional level, before investigating the work of GTAs in art and design.

\section{Background to the Case}

The Higher Education Funding Council for England (HEFCE) Catalyst Fund supports a national program of projects to tackle barriers to student success. As part of this program, the two-year "Intervention for Success" project is a collaboration across four partner universities to develop a range of initiatives and interventions to address identified issues of differential achievement and retention. When identifying specific interventions, as recommended by Thomas et al. (2017), data analytics were utilized to provide a deeper understanding of the local contexts (disciplines, courses, and characteristics of student groups) that may influence student retention and attainment. In light of the institutional data, the foci of one of the partner universities included a range of interventions aimed to: Develop a 
sense of well-being and belonging to the university; establish positive relationships between peers, staff and wider university services; and encourage proactivity and a curiosity to discover. One aspect of these initiatives was the introduction of a full-time, paid Graduate Teaching Assistant (GTA) role, with a focus on fostering a bridge between students and staff. This is in contrast to a more traditional student-student peer mentoring role, which already exists at the institution. In line with the devolved approach of student academic support across the university, the GTAs were recruited at a school-based level to work primarily with first year students of courses with a large student cohort.

Overall, five out of seven schools across the university recruited GTAs. The GTA role had a generic job description with a focus centered on supporting teaching, and successful candidates were given a general induction as new staff members, which included orientation to university services and systems and training on data management and diversity and inclusion. The devolved structure of the schools within the institution enabled the GTA role to be tailored according to the specific needs of the school. This allowed the GTAs to develop individual roles which were unique to the requirements of the courses and student groups they worked with (Figure 1). In the case of the School of Art, Design and Architecture (ADA), prior to recruiting the GTAs, subject lecturers attended a workshop to discuss the ways that GTAs might support student engagement in each course. However, course teams were mandated not to use the GTAs to relieve teaching loads, and instead to consider what activities could be done by GTAs to foster course communities and to manage the pastoral and affective needs of large cohorts. This participative approach helped staff both to analyze the particular areas of need for each course and also helped foster support and enthusiasm for the initiative. As such, the GTAs in ADA developed a unique way of working with students, which involved having a presence in the studio, but not teaching particular sessions or modules. This is in contrast to GTAs in other schools in the institution and also at other universities, where they are primarily employed to teach workshops, seminars and tutorials, akin to a traditional graduate tutor role.
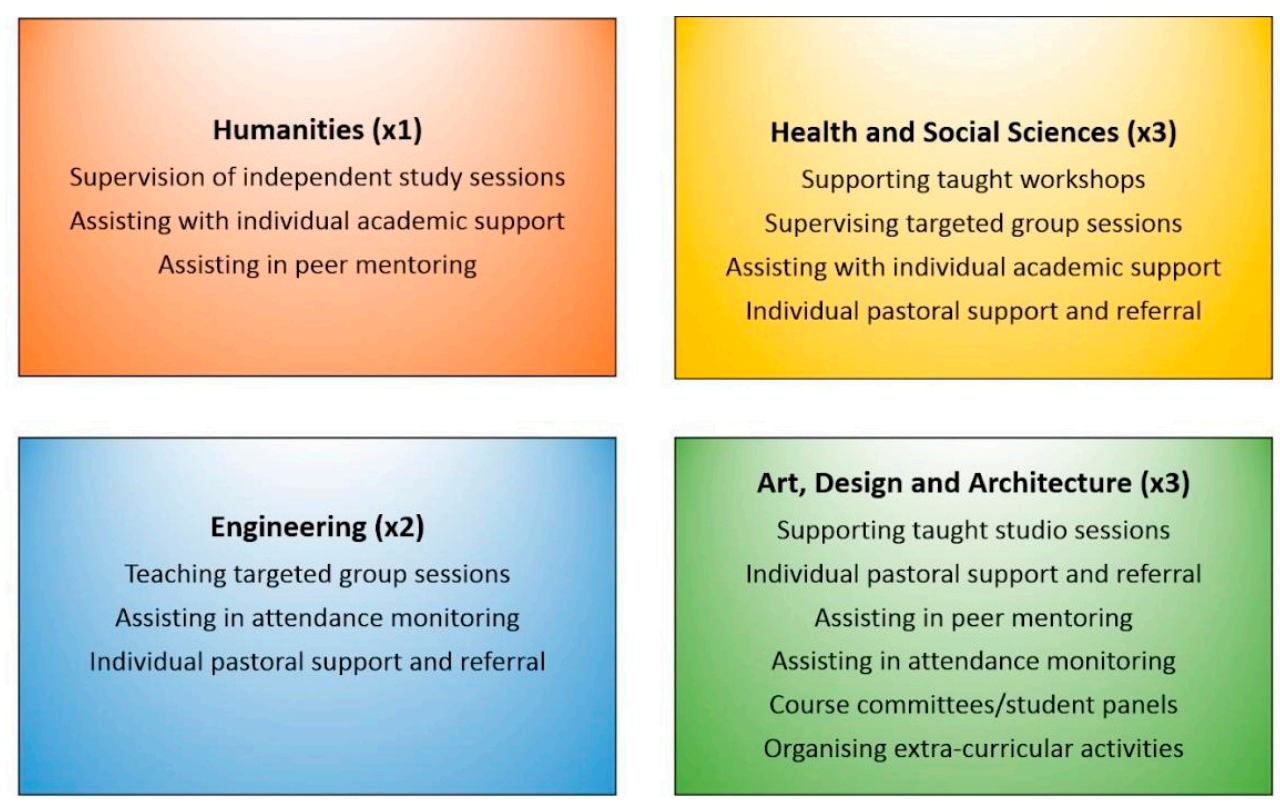

Figure 1. Graduate Teaching Assistant (GTA) activities in different Schools.

The GTAs in ADA are each responsible for one department each, and work directly with students on the undergraduate courses in their department. All three GTAs were recent graduates from courses in the institution and department they were supporting and so already knew the course, department, and institutional structures, as well as many of the key teaching staff. Rather than add numbers to the teaching faculty, the aim was for the GTAs to use their own experience as students to enable them to provide an approachable, friendly, and knowledgeable point of contact for current students, 
and therefore to act as a communication bridge between tutors and students. The GTAs developed a number of ways to get to know the first year students, which included regular attendance at studio or workshop sessions for every course, organizing extracurricular activities, and attending course committee and student panel meetings (see Figure 1). The GTAs were also provided with mobile phones for contacting students, as they found that students were more comfortable communicating via text message, rather than by more formal email.

\section{Analysing Initial Impact}

Initially the project was evaluated by monitoring retention rates for first year students in the School of Art, Design and Architecture. One lecturer commented:

I can say with certainty the retention data has improved to date... The scheme therefore has been a success, and clearly sets a precedent that indicates when such things are invested in, improvement occurs. (Lecturer 9)

As the quote indicates, retention figures were noted to have improved substantially, and by the end of the year, the school had moved from the lowest to the best-performing school in the institution. It is also clear that subject lecturers embraced the support from the GTAs, and in contrast to many of the experiences detailed in the literature (see Raaper 2018; Smith and Smith 2012), the GTAs were considered a welcome addition to the school by both staff and students. In order to explore these positive outcomes further, it was important to understand how exactly the GTAs were working with students and to analyze this in terms of the literature on art and design education.

To assess the initial impact of the GTA initiative on student engagement in more detail, qualitative feedback was sourced from first year students and course leaders. Ethical approval was granted by the School Ethics Committee and informed consent obtained from all participants. First year students $(n=564)$ in the school were emailed by their first year tutors and invited to voluntarily complete an anonymous online survey, which asked them to comment, positively and/or negatively, on their experiences with their GTA. Course leaders $(n=16)$ were contacted via email for their feedback on how the GTAs had integrated within their course, any perceived impact (positive and negative), and thoughts on future directions for the initiative. The three GTAs were invited to participate in a focus group, lasting 50 minutes, to consider the role from their perspective.

To achieve a quick visual view of the student survey results, the responses were examined for word frequency and prominence (the larger the word font size in the image, the more prevalent the term in the data set) using the open-source online tool Wordle (Frienberg 2014; see also Seale 2018, p. 409). As shown in Figure 2, student feedback on the initiative was overwhelmingly positive, with the overriding response being how 'helpful' the GTAs have been for first year students. Following this initial word frequency view, the student survey data was then examined in more detail using inductive thematic analysis (Braun and Clarke 2006).

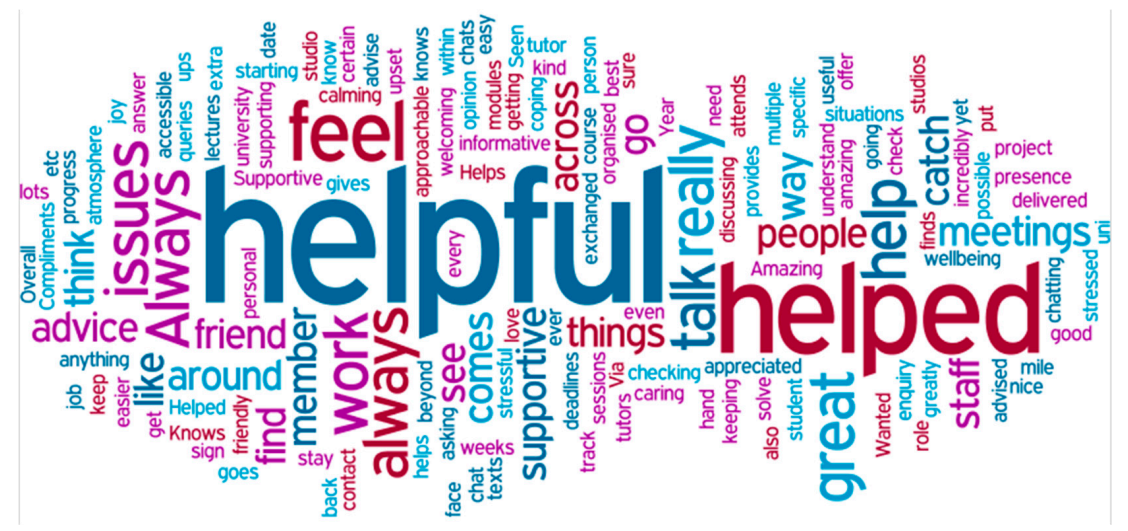

Figure 2. Visual frequency display of student survey data. 


\subsection{Navigating University Life}

Two general themes have emerged from the data analysis, the first and, as stated above, most overriding of which is "helpful and supportive". First year students expressed the challenges of transitioning into a higher education environment and how the GTAs had provided welcomed individual support:

I have been having meetings with her and feel like she has helped and advised me in the best way possible with any issues I have had and she's helped me stay on track with my uni work. (Student 13)

[She] helped me when starting the course as I was getting stressed and upset about multiple things and has had chats with me, helped me sign up for Wellbeing [services]. (Student 3)

In addition to the appreciation of support from the students, one lecturer explained that one of the major benefits of the GTAs was the fact that they were able to "build clear narratives for each student" (Lecturer A), and another appreciated the "extra level of support" (Lecturer G) provided by the GTAs. As Orr and Shreeve (2018, p. 150) point out, "there is usually no time for tutors to delve into the affective responses and the personal histories of the many students in a course." This lack of time for tutors to get to know each student individually is in tension with the fact that students frequently expect to be taught by supportive tutors who value and respect them as individuals (see Austerlitz et al. 2008; Austerlitz 2007). It seems that one of the most important functions of the GTAs is to contribute towards the students feeling that there are staff who have the time to get to know them and who can support them with their individual needs and issues.

Students also valued the fact that the GTAs would follow up with students to find out how the students were getting on. Students who had mentioned issues to the GTAs reported that the GTAs would follow up with "catch-ups every few weeks to see how I was coping" (Student 3). Other students who had not sought support themselves from the GTAs still noticed that they were "always checking up on people" (Student 14). The GTAs were also involved in spotting patterns in attendance data to identify students who were absent and may be at risk of disengaging with the course. The GTAs reported that students were often surprised that their non-attendance in a session had been personally noticed, particularly if they were part of a larger cohort. As such, the GTAs enabled these students to feel "visible", and facilitated a sense of belonging by signposting that someone is missing from the community. As Austerlitz (2007) found, when students start university they expect to quickly feel as though they "belong" to the university and their course community. A lack of a feeling of belonging is also the most common reason students give for leaving university courses (Thomas 2012).

The second general theme in the data was the "communication bridge" that the GTAs formed between students and tutors. GTAs were seen by students as being "approachable" (Student 4) and "accessible" (Student 10). Teaching staff commented that "it has helped students feel at ease as they have another point of contact" (Lecturer C) for issues, if and when they arose. Having another person to consult resonated with students who lacked confidence in speaking to their tutors themselves, with the GTAs becoming an effective bridge for communication and an advocate for the student's voice:

... reassuring knowing there is someone I can reach out to who understands our needs as students fully and is able to communicate that to our course leaders in a way we are unable. (Student 15)

Students recognized that this was due to fact that the GTAs are recent graduates of their university, and they commented that this meant that the GTAs "can understand any problems you are having" (Student 17). This privileged status was also acknowledged by a course leader:

The GTA has had a beneficial impact upon student interaction with the department ... The key issue is that she is a recent graduate. Not much older than the students she has 
to work with and has recent firsthand experience of being a student ... ensuring that the student's voice is heard at formal meetings and feeding back discussions and issues with the wider group. (Lecturer F)

One student described that the GTAs are "seen as a staff member [but] more accessible to students" (Student 10). The fact that GTAs use mobile phones, including text messages, to contact students has also helped to differentiate them from tutors as well as enabling them to have a more familiar and informal communication channel with students. Figure 3 encapsulates the communication flows between the students and the staff they encounter on their course. In addition to their subject tutor, personal academic tutors provide pastoral guidance. Students can also seek support from school-based academic skills tutors for the development of written assignments, as well as technicians for advice on technical matters relating to their practical design work. Student peer mentors, with some supervision from the GTAs, are available primarily to first year students to aid their transition into university life, and informal peer-to-peer conversations may also occur within the studio. Although all of these different support roles have a clear communication channel with students, it is apparent that the GTAs are central in supporting the student experience. They have the highest proportion of two-way communication (colored green), connecting across the entire range of ADA support roles on behalf of primarily students, but also the subject tutor. This "proxy" role can help raise student awareness of the range of support available and may help students negotiate any barriers or reticence in accessing this.

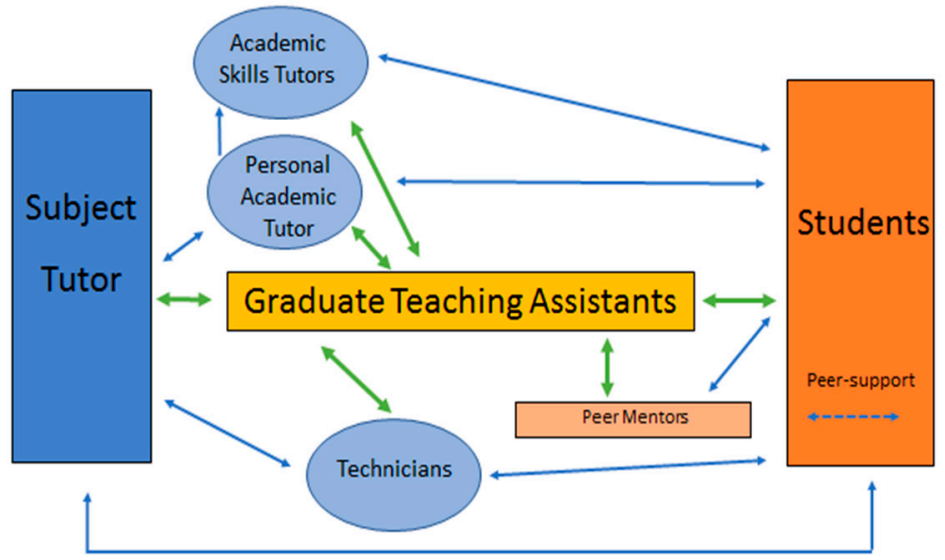

Figure 3. Student support and communication channels in the case study.

The two-way communication channels, combined with approachability and accessibility, seem to have helped to bridge the gap between subject tutor and students. Students were happy to have a chat with the GTAs about any issues, seeing them as "Easy to talk to. Someone you can trust" (Student 17), but also as "more of a friend" (Student 12). Creating and maintaining this delicate balance between the friendly, approachable face for students, whilst still being a staff member, is one of the challenges yet unique properties of the GTA role. The GTAs themselves reported the most demanding aspect of their role was learning how to develop clear boundaries between the students and themselves, by maintaining a professional distance and being clear about when students can expect them to be available. All three GTAs said that although they have been given mobile phones by the university for contacting students, they make sure they switch these off at the end of the working day so that they are not drawn into responding to students when not on duty. However, the GTAs also commented that they would have benefited from a more comprehensive induction program as much of the training they undertook, such as mental health awareness, was initiated by them in response to issues that arose whilst undertaking the role. 


\subsection{Supporting Studio Work}

In addition to the two general themes mentioned above, GTAs were also perceived to make a valuable contribution to the student experience of studio work. In particular, the GTAs developed an important role in helping students adjust to the "state of mind" of the studio (Orr and Shreeve 2018, p. 156). Students commented that the GTAs help them to "understand certain modules" (Student 1) and made clearer the "puzzling aspects of the course" (Student 18). This was especially important for those students who had not undertaken an arts foundation course prior to arrival. For example, some students were unfamiliar with how to curate a sketchbook, and as one GTA pointed out, "It's just gluing and sticking, but then I've always done them" (GTA X). The GTAs also encouraged students to exploit the resources available to them, including the knowledge and expertise of the technicians "to help them through the sticky patches of learning to become creative practitioners" (Orr and Shreeve 2018, p. 148). One of the GTA's cited the example of a student who almost disengaged from their course as they felt the first term was not challenging enough and was repeating information that they had already covered in their previous studies. The GTA helped the student to recognize the range of expertise and equipment that was on offer, and how to be an independent learner and harness resources for their own creative development.

The GTAs also reported talking to students who were 'stuck' in the studio and then encouraging them to experiment by producing a range of variations to "see what they look like" (GTA X). Following these experiments, GTAs then modeled to students "an appropriate and discipline-specific language of evaluation" (Austerlitz et al. 2008, p. 141), by talking to students about which ones they liked and why. The GTAs described that much of their discussions with students were about "giving them the idea there isn't a right and wrong answer" (GTA Y). In a similar manner to the students in the Orr et al. (2014) study, one of our GTAs explained: "The penny dropped in final year that you are not taught the subject but how to approach the subject" (GTA X), and that their role was to help first year students understand this earlier.

One of the key functions that evolved from attending studio sessions was that the GTAs got to know the students' work and also acted as a soundboard in the studio. One student commented:

She has shown great interest in our work as a group and individuals, this included making helpful suggestions and asking questions of us. (Student 18)

By asking students about their work, they encouraged students to talk about their ideas and inspiration and processes, and thus "develop fluency in the language of the discipline" (Orr and Shreeve 2018, p. 153). Students quickly realized that the GTAs were different to tutors in that they were not there to judge their work or to develop it, but could listen and reflect back the student's own thoughts about it. A number of students developed a preference for talking to GTAs by asking, "Can I go through it with you?" as a quasi-rehearsal before a crit session. Students commented that the GTAs were "always chatting and asking how you are, how you feel about work etc.; Compliments your work!" (Student 4). GTAs also had an important role to play in helping students reconcile different viewpoints on their work given by different tutors. As Orr et al. (2014) point out, this is one of the most contentious areas for students, and the discussions with GTAs helped students to contextualize their work in relation to their discipline as a whole, rather than as a purely personal, and therefore highly emotional endeavor (see Elkins 2001; Orr and Shreeve 2018).

\section{Conclusions}

This study has explored the initial impact of graduate teaching assistants in studio-based art and design courses at one institution. Students have found their presence helpful and supportive and welcome the fact that, as a staff member with a student perspective, they provide a bridge to help them communicate with tutors. The GTA's discipline knowledge has also enabled them to help new students navigate and adapt to studio culture, and has helped make explicit to students some of the more unspoken or hidden aspects of art and design pedagogy. In contrast to previous studies on 
the use of GTAs in higher education, tutors in this case study have overwhelmingly welcomed the additional support in a time of increasing student numbers and consequent pressures on studio-based teaching. The fact that tutors were consulted and helped to define the role may have contributed to the positive reception for what could have been a controversial initiative. The GTAs themselves have highlighted the rewarding aspects of supporting students to achieve their potential, but have also pointed out that a more comprehensive induction program needs to be developed for the GTA role.

This study has detailed the initial phase of this initiative and it is clear that more in-depth longitudinal research is needed to evaluate the project further. Whilst initial data indicate that the school now leads the institution in terms of retention, it will be interesting to see how these gains are sustained, and to analyze in more detail the contribution of the GTAs to this. Future directions for the GTA role include extending the support to second and final year students, including the development of a more established student peer mentoring program to encourage greater horizontal communication between students, and a more collaborative culture in the studio. However, early indications show that the graduate teaching assistant role, as detailed in this case study, goes some way to providing a life-line for the pedagogic golden goose that is studio teaching.

Author Contributions: All authors contributed equally to the research, writing, and editing of this article.

Funding: This research received no external funding.

Acknowledgments: We would like to thank Bethany Morgan, Eleanor Smith and Sophie Lupton for sharing their experiences with us. In addition, we would like to thank Professor Song $\mathrm{Wu}$ for permission to compile and disseminate this case study.

Conflicts of Interest: The authors declare no conflict of interest.

\section{References}

Akalin, Aysu, and Ihsan Sezal. 2009. The Importance of Conceptual and Concrete Modelling in Architectural Design Education. International Journal of Art E Design Education 28: 14-24. [CrossRef]

Austerlitz, Noam. 2007. The Internal Point of View: Studying Design Students' Emotional Experience in the Studio via Phenomenography and Ethnography. Art, Design \& Communication in Higher Education 5: 165-77.

Austerlitz, Noam, Margo Blythman, Annie Grove-White, Barbara Anne Jones, Carol Ann Jones, Sally J. Morgan, Susan Orr, Alison Shreeve, and Suzi Vaughn. 2008. Mind the gap: Expectations, ambiguity and pedagogy within art and design higher education. In The Student Experience in Art and Design: Drivers for Change. Edited by Linda Drew. Cambridge: GLAD/Jill Rogers Associates, pp. 125-48.

Belfield, Chris, Jack Britton, Lorraine Dearden, and Laura van der Erve. 2017. Higher Education Funding in England: Past, Present and Options for the Future. IFS Briefing Note BN211. London: Institute for Fiscal Studies, Available online: https:/ / www.ifs.org.uk/uploads/publications/bns/BN211.pdf (accessed on 17 September 2018).

Braun, Virginia, and Victoria Clarke. 2006. Using Thematic Analysis in Psychology. Qualitative Research in Psychology 3: 77-101. [CrossRef]

Browne, John. 2010. Securing a Sustainable Future for Higher Education: An Independent Review of Higher Education Funding and Students Finance; Browne Report. London: HMSO. Available online: https://www.gov.uk/ government/publications / the-browne-report-higher-education-funding-and-student-finance (accessed on 17 September 2018).

Bunce, Louise, Amy Baird, and Siân E. Jones. 2017. The Student-as-Consumer Approach in Higher Education and its Effects on Academic Performance. Studies in Higher Education 42: 1958-78. [CrossRef]

Burke, Penny Jane, and Jackie McManus. 2011. Art for a Few: Exclusions and Misrecognitions in Higher Education Admissions Practices. Discourse: Studies in the Cultural Politics of Education 32: 699-712. [CrossRef]

Caldwell, Elizabeth, and Jodi Gregory. 2016. Internationalizing the Art School: What Part Does the Studio Have to Play? Art, Design \& Communication in Higher Education 15: 117-33. [CrossRef]

Consumer Rights Act. 2015. c.15. Available online: http://www.legislation.gov.uk/ukpga/2015/15/contents / enacted (accessed on 17 September 2018). 
Dearing, Ronald. 1997. Higher Education in the Learning Society; Report of the National Committee of Enquiry into Higher Education. London: HMSO. Available online: http:/ /www.educationengland.org.uk/documents / dearing1997/ dearing1997.html (accessed on 17 September 2018).

Department for Education. 2018. Prime Minister Launches Major Review of Post-18 Education. Available online: https: / / www.gov.uk/government/news/prime-minister-launches-major-review-of-post-18-education (accessed on 13 September 2018).

Dineen, Ruth, and Elspeth Collins. 2005. Killing the Goose: Conflicts between Pedagogy and Politics in the Delivery of a Creative Education. International Journal of Art E Design Education 24: 43-52. [CrossRef]

Elkins, James. 2001. Why Art Cannot Be Taught: A Handbook for art Students. Urbana: University of Illinois Press.

Finnigan, Terry, and Aisha Richards. 2016. Retention and Attainment in the Disciplines: Art and Design. York: Higher Education Academy, Available online: https://www.heacademy.ac.uk/system/files/ug_retention_and_ attainment_in_art_and_design2.pdf (accessed on 17 September 2018).

Frienberg, Jonathan. 2014. Wordle. Available online: http:/ / www.wordle.net/create (accessed on 14 September 2018).

Hammersley-Fletcher, Linda, and Michelle Lowe. 2011. From General Dogsbody to Whole-Class Delivery-The Role of the Primary School Teaching Assistant within a Moral Maze. Management in Education 25: 78-81. [CrossRef]

HESA. 2018. Graduate Outcomes. Available online: https:/ /www.hesa.ac.uk/innovation/outcomes (accessed on 13 September 2018).

Higher Education and Research Act. 2017. c.29. Available online: http://www.legislation.gov.uk/ukpga/2017/ 29/contents/enacted (accessed on 17 September 2018).

Kahu, Ella R., and Karen Nelson. 2018. Student Engagement in the Educational Interface: Understanding the Mechanisms of Student Success. Higher Education Research \& Development 37: 58-71. [CrossRef]

McRae, Andrew. 2018. What Does 'Value for Money' Mean for English Higher Education? Times Higher Education. February 22. Available online: https:/ / www.timeshighereducation.com/features/what-does-value-moneymean-english-higher-education (accessed on 17 September 2018).

Office for Students. 2018. Office for Students. Available online: https://www.officeforstudents.org.uk/ (accessed on 13 September 2018).

Orr, Susan, and Alison Shreeve. 2018. Art and Design Pedagogy in Higher Education: Knowledge, Values and Ambiguity in the Creative Curriculum. London: Routledge. London: Routledge.

Orr, Susan, Mantz Yorke, and Bernadette Blair. 2014. 'The Answer is Brought about from within You': A Student-Centred Perspective on Pedagogy in Art and Design. International Journal of Art E Design Education 33: 32-45. [CrossRef]

Raaper, Rille. 2018. 'Peacekeepers' and 'Machine Factories': Tracing Graduate Teaching Assistant Subjectivity in a Neoliberalised University. British Journal of Sociology of Education 39: 421-35. [CrossRef]

Richards, Aisha, and Terry Finnigan. 2015. Embedding Equality and Diversity in the Curriculum: An Art and Design Practitioner's Guide. York: Higher Education Academy, Available online: https:/ / www.heacademy.ac.uk/ node/11103 (accessed on 17 September 2018).

Seale, Clive. 2018. Researching Society and Culture, 4th ed. Los Angeles: SAGE.

Sims, Ellen, and Alison Shreeve. 2012. Signature pedagogies in art and design. In Exploring More Signature Pedagogies: Approaches to Teaching Disciplinary Habits of Mind. Edited by Nancy L. Chick, Aeron Haynie, Regan A. R. Gurung and Anthony A. Ciccone. Stirling: Stylus, pp. 55-67.

Smith, Korydon, and Carl Smith. 2012. Non-Career Teachers in the Design Studio: Economics, Pedagogy and Teacher Development. International Journal of Art \& Design Education 31: 90-104. [CrossRef]

Sovic, Silvia. 2008. Lost in Transition? The International Students' Experience Project. London: CLIP CETL.

Swann, Cal. 1986. Nellie is Dead. Designer 1: 18-20. [CrossRef]

Thomas, Liz. 2012. Building Student Engagement and Belonging in Higher Education at a Time for Change: Final Report from the What Works? Student Retention E Success Programme. London: Paul Hamlyn Foundation, Available online: https:/ / www.heacademy.ac.uk/system/files/what_works_summary_report_0.pdf (accessed on 17 September 2018).

Thomas, Liz, Michael Hill, Joan O'Mahony, and Mantz Yorke. 2017. Supporting Student Success: Strategies for Institutional Change: Summary Report from the What Works? Student Retention \& Success Programme; London: Paul Hamlyn Foundation. Available online: https: / www.heacademy.ac.uk/system/files/hub/download/ what_works_2_-_full_report.pdf (accessed on 17 September 2018). 
Universities UK. 2017. Around a Half of Students now See Themselves as Customers of Their University-New ComRes Survey. Available online: https://www.universitiesuk.ac.uk/news/Pages/Around-a-half-ofstudents-now-see-themselves-as-customers-of-their-university.aspx (accessed on 13 September 2018).

(c)

(C) 2018 by the authors. Licensee MDPI, Basel, Switzerland. This article is an open access article distributed under the terms and conditions of the Creative Commons Attribution (CC BY) license (http://creativecommons.org/licenses/by/4.0/). 